\title{
O EMPREGO DA ARBORIZAÇÃO NA MANUTENÇÃO DA BIODIVERSIDADE DE FAUNA EM ÁREAS URBANAS
}

Flávia Gizele König Brun ${ }^{1}$, Dionísio Link², Eleandro José Brun³

\section{RESUMO}

A biodiversidade de entomofauna e avifauna em ambientes urbanos foi estudada por meio de revisão bibliográfica. Com o objetivo de demonstrar a importância da arborização urbana como forma de manutenção da biodiversidade da fauna dentro dos centros urbanos brasileiros e as principais práticas a serem adotadas em planos de arborização urbana para conservação da fauna nestes ambientes, foi avaliada a literatura existente, com a revisão de diversos trabalhos que apontam que a função da arborização de centros urbanos reflete-se diretamente na manutenção de abrigos e na diversificação de fontes de alimento para a fauna urbana, principalmente para espécies de hábitos generalistas, mais beneficiadas, mas, também, para espécies de hábitos mais específicos, que habitam áreas de florestas que circundam as cidades. Desta forma, a manutenção, o aumento de áreas e a interligação das áreas verdes urbanas e também peri-urbanas são fundamentais, usando-se para isso, de preferência, espécies nativas e um maior numero de espécies, visando diversificar também as fontes de alimentos.

Palavras-chave: arborização urbana, biodiversidade, abrigo, fauna.

1. Eng. Florestal, Acadêmica do Curso de Especialização em Educação Ambiental - CCR/UFSM. Santa Maria, RS. E-mail: flaviakonig@mail.ufsm.br.

2. Eng. Agrônomo, Prof. Dr. do Departamento de Defesa Fitossanitária - CCR/UFSM. Santa Maria, RS. E-mail: dlink@ccr.ufsm.br.

3. Eng. Ftal., Doutorando do Programa de Pós-graduação em Engenharia Florestal - CCR - UFSM. Santa Maria, RS. E-mail: eleandrojbrun@yahoo.com.br. 


\title{
THE ARBORIZATION USE IN THE FAUNA BIODIVERSITY MANUTENTION IN URBAN AREAS
}

\begin{abstract}
The entomofauna and avifauna biodiversity in urban places was studied through bibliographical revision. With the objective of demonstrate the importance of the urban trees inside as form of maintenance of the biodiversity of the fauna of the Brazilian urban centers and the practical principal to be adopted in plans of urban trees for conservation of the fauna in these environment, the existent literature was evaluated, with the revision of several works that point that the function of the trees of urban centers is reflected directly in the maintenance of shelters and in the diversification of food sources for the urban fauna, mainly for species of generic habits, more beneficiaries, but also for species of more specific habits, that inhabit areas of forests that surround the cities. So, the maintenance, the increase of areas and the link of the urban and also peri-urban green areas are fundamental, being used for that, preferably, native species and a larger one number of species, seeking to also diversify the food sources.
\end{abstract}

Key-words: urban trees, biodiversity, shelter, fauna. 


\section{INTRODUÇÃO}

O ambiente urbano é a resultante das interações dos fatores ambientais, biológicos e sócio-econômicos, onde o meio edificado pelo homem predomina sobre o meio físico, causando profundas alterações sobre este e na qualidade de vida dos seres (Lombardo, 1990).

O adensamento urbano leva à formação de inúmeros microecossistemas, os quais refletem diretamente na fauna urbana, o que a torna resultante de fatores tanto ecológicos como históricos e, portanto, não originada, somente, pela depauperação da composição faunística, original pelo processo de urbanização, mas, também, pela constante introdução de espécies (Japyassú \& Brescovit, 2006).

A urbanização modifica a estrutura física e biótica do hábitat, podendo afetar diversos processos ecológicos que envolvem a fauna e a flora nestas áreas. Como resultado da intervenção antrópica, a paisagem urbana geralmente se apresenta fragmentada em um mosaico de diferentes ambientes e, tanto a estrutura da vegetação, quanto a sua composição florística, costumam diferir daquela originalmente presente, disponibilizando, portanto, condições e recursos distintos a serem explorados pela fauna (Mendonça \& Anjos, 2005).

Neste sentido, Silva \& Magalhães (1993) afirmam que a arborização urbana garante a integração dos espaços habitados às regiões circunvizinhas, possibilitando a continuidade da trama biológica e das características climáticas e ambientais, sendo, desta forma, evitadas as ilhas de calor, desertos biológicos e o desconforto ambiental que caracterizam as cidades sem proteção vegetal adequada.

Nesta estrutura modificada, a arborização realizada, em muitas cidades, com o uso de poucas espécies e ainda de forma descontínua, propicia perdas de biodiversidade, ou seja, as espécies de fauna que poderiam visitar áreas urbanas, não são atraídas para tal em função de abrigos precários e pouca fonte de alimentação. Nestas condições, apenas poucas espécies conseguem sobreviver em áreas urbanas.

Com base nestes aspectos, o presente trabalho de revisão tem por objetivo demonstrar a importância da arborização urbana como forma de manutenção da biodiversidade da fauna dentro dos centros urbanos brasileiros e as principais práticas a serem adotadas em planos de arborização urbana para a conservação dessa fauna, nestes ambientes. 


\section{A arborização urbana e a biodiversidade de entomofauna}

Atualmente, devido às grandes alterações geradas pelas atividades humanas, principalmente pelo processo de urbanização, é de grande importância a realização de trabalhos de avaliação da alteração da fauna devido à influência humana e recursos necessários para sua sobrevivência.

No estudo de Taura \& Laroca (2001), sobre a associação de abelhas silvestre a um biótopo urbano (Passeio Público) em Curitiba, PR, os autores observaram, em avaliações consecutivas durante os anos de 1975, 1986/1987 e 1992/1993, que, em número de espécies, predominou a família Halactidae, com 32 espécies; porém, devido às atividades humanas, como poluição do ar, ruídos, tráfego intenso, presença de visitantes, jardinagem contínua e introdução de espécies vegetais, ocorreu uma simplificação crescente na composição avifaunística, que, por sua vez, favoreceu a organização de populações da família Apidae em colônias, sendo representada, predominantemente, pelas espécies: Trigona spinipes, Plebeia emerina e Partamona helleri, que teve sua presença identificada a partir da segunda avaliação.

De acordo com os autores acima, os fatores que favoreceram a família seriam a disponibilidade de fontes de alimento ao longo de todo o período anual, devido a constante introdução de espécimes com floração, durante todo ano, que garantem atividade de vôo até no inverno, e, também, pela formação de locais propícios para nidificação, em ambientes artificiais, como a realização de dendrocirurgias em árvores atacadas por cupins e retirada constante de colônias de Apis mellifera por funcionários do parque.

Porém, ainda neste estudo, observaram o favorecimento de algumas espécies e também notaram a redução ou desaparecimento de outras espécies, como é o caso das espécies Bombus atratus, Neocorynura aenigma, Hyaleus rivalis, Dialictus sp., Panurginae sp., o que se deve essencialmente à retirada de plantas da composição paisagística, como Polygonum punctatum e Muehlenbeckia platyclada pela prática da jardinagem no local e pela diminuição da área de solo exposto pelo asfaltamento.

Souza et al. (2005), avaliando abelhas sem ferrão residentes no Campus Federação/Ondina, na Universidade Federal da Bahia, Salvador, BA, observaram situação semelhante à relatada anteriormente, onde ocorreu a predominância de espécies de Meloponina com 94 ninhos, representado pelas espécies: Tetragonisca angustula, Trigona spinipes, Oxytrigona tataira, Plebeia droryana e Nannotrigona testaceicornis, em ambientes antropizados, favorecidos preferencialmente pela grande variedade de locais para nidificação e oferta de recursos tróficos. Sendo que, destes fatores, a arborização do campus exerceu papel preponderante para a nidificação das espécies, onde estas se alojaram tanto em árvores vivas como mortas, e entre as árvores vivas foram representadas 
na maioria, por espécies introduzidas como: a Mangueira (Mangifera indica), o Jambolão (Eugenia jambolana) e a Amendoeira (Terminalia catappa), que, segundo os autores, favorecem significativamente a manutenção das populações de Meloponina, em conjunto com os resquícios de Mata Atlântica existentes.

Agostini \& Sazima (2003), avaliando plantas ornamentais e seus recursos para abelhas, na arborização do Campus da Universidade Estadual de Campinas, SP, catalogaram 42 espécies de plantas arbóreas e arbustivas visitadas por abelhas sendo que $62 \%$ destas espécies eram nativas. Foram registradas 17 espécies de abelhas em visitas a flores, sendo destas destacadas: Trigona spinipes, Apis mellifera e Tetragonisca angustula, visitando em torno de 28 a 35 espécies da arborização, onde 55\% destas espécies utilizaram o pólen e o néctar, mas em espécies como o Urucum (Bixa orelana), Rosabrasileira (Cochlospermum vitifolium), Cassia-rosa (Cassia grandis), Falso-barbatimão (Cassia leptophylla), Acácia-imperial (Cassia fistula), Resedá-gigante (Lagerstroemia speciosa), Pau-santo (Kielmeyra coriacea), Chuva-de-ouro (Senna multijuga) e Quaresmeira (Tibouchina granulosa), apenas o pólen foi utilizado, devido à presença de anteras poricidas.

Com base nas especializações e peculiaridades apresentadas pelas abelhas, os autores sugerem que é importante o desenvolvimento de planos de manejo de arborização urbana que usem plantas ornamentais nativas que apresentem um longo período de floração, pois representam uma fonte extra de recursos garantida para abelhas de matas circunvizinhas, transformando o ambiente urbano em corredor biológico, conectando fragmentos florestais próximos. Além disto, as abelhas cumprem um papel crucial na manutenção da biodiversidade dos ecossistemas naturais e o conhecimento das interações dessas abelhas com suas plantas preferidas são imprescindíveis para o manejo destes ecossistemas.

Ruszczyk \& Nascimento (1999), observando a biologia de borboletas da espécie Methona themisto em praças públicas de Uberlândia, MG, verificaram que, em áreas urbanas, os recursos alimentares disponíveis para os adultos das borboletas são fatores ecológicos que são freqüentemente limitantes, tornando espécies da arborização urbana como o Ligustro (Ligustrum japonicum), árvore exótica originária da Ásia e abundante na arborização de cidades brasileiras, favorável para esta espécie de borboleta, que se caracteriza como oportunista, por utilizar diferentes fontes de alimentação, especialmente nas áreas verdes com vegetação exótica, o que lhe garante uma vida relativamente longa, com apreciável abundância ao longo do ano, embora as condições de alto trânsito de cidadãos, veículos e ar poluído, colocam esse lepidóptero como uma das espécies apropriadas para ter sua condição de vida melhorada em praças e parques de regiões centrais de cidades, através do plantio de vegetais que forneçam néctar para os adultos, como Calliandra selloi, Ixora spp., Lantana camara, etc. 
Conforme Franchin \& Marçal Júnior (2004), aves e borboletas são dois grupos que respondem de modo semelhante à urbanização, sendo considerados importantes bioindicadores, razão pelos quais são utilizados amplamente no desenvolvimento de planos de conservação.

\section{A arborização urbana e a diversidade de avifauna em cidades}

A presença da avifauna brasileira em ambientes modificados pela ação antrópica, como as áreas urbanas, tem se tornado comum, já que, devido à diversificação do ambiente, tendem a sofrer variações menos acentuadas de recursos, mantendo sua diversidade de avifauna constante, o que explica a presença de $31 \%$ das aves brasileiras estarem representadas nestes ambientes (Franchin et al., 2004).

Pereira et al. (2005), estudando a utilização de espécies vegetais da arborização urbana de Recife como instrumento de biodiversidade da avifauna silvestre, concluíram que 13 espécies da avifauna, entre elas: o Bem-te-vi (Pitangus sulphuratus), o bem-te-vi pequeno (Myiozetetes similis), frei-vicente (Tangara cayana), a jandaia-estrela (Aratinga aurea), a jandaia-gangarra (Aratinga cactorum), a jandaia-verdadeira (Aratinga jandaya), o maracanãzinho (Diopsitaca nobilis), o periquito-de-asa-amarela (Brotogeris chiriri), o sabiábranco (Turdus leucomelas), o sabiá-gongá (Turdus rufiventris), sanhaçu-de-bananeira (Thraupis sayaca), o Sanhaçu-de-coqueiro (Thraupis palmarum) e o Tuim (Forpus xanthopterygius) se alimentavam exclusivamente de frutos oferecidos por espécies da arborização pública, sendo a espécie preferencial a Palmeira-imperial (Roystonea oleraceae).

Porém, estes autores colocam um fato muito agravante em seu estudo, que dos 8.086 exemplares da arborização urbana de Recife, apenas 172 exemplares (2,1\%), distribuídos em apenas 11 espécies, apresentavam frutos comestíveis à avifauna, e alertam para a necessidade da inclusão de espécies frutíferas em planos de arborização urbana por parte dos órgãos públicos responsáveis pela questão.

Lima \& Aleixo (2000), estudando aves em ambientes antropizados da cidade de Campinas, observaram que espécies como a Choca-barrada (Thamnophilus doliatus) apresentaram presença regular em ambientes urbanos somente em parques e bairros bem arborizados, sendo considerado o único Formicariidae que se adaptou ao ambiente urbano. Também segundo estes autores, espécies migratórias, como é caso do Gaturamo-rei (Euphonia cyanocephala), o qual aparece em parques e bairros mais arborizados entre os meses de Abril e Junho, têm sua presença diretamente ligada à frutificação de Phoradendron rubrum, uma erva-de-passarinho, que serve de alimentação a esta ave, hemiparasita do Cinamomo (Melia azedarach), muito utilizado na ornamentação de ruas. 
Além desta espécie, os autores citados, relatam o caso de outra ave migratória local, que é o Saí-andorinha (Tersina viridis), um frugívoro que migra para Campinas nos meses de março a maio, acompanhando a frutificação da Magnólia-amarela (Michelia champaca), empregada na arborização da cidade.

Quanto ao comportamento de beija-flores em áreas urbanas, Mendonça \& Anjos (2005), avaliando estas aves e seus recursos florais no Campus da Universidade Estadual de Londrina, PR, verificaram que, de um total de 22 espécies vegetais visitadas, a maioria (>60\%) apresentava origem exótica, sendo, destas, 45,4\% de porte arbóreo e 40,9\% arbustivas, e apenas 6 espécies apresentavam caráter fenológico de floração ao longo de todo ano, tais como: Sanchezia nobilis, Thunbergia grandiflora, Carica papaya, Hibiscus rosa-sinensis, Malvaviscus arboreus e Bouganvillea spectabilis. Porém, dentro do grupo de espécies vegetais observadas, apenas 7 se caracterizaram como recursos tróficos efetivos para a comunidade de beija-flores estudada: Sphatodea campanulata, Erthryna speciosa, Stifftia chrysantha, Malvaviscus arboreus, Tabebuia avellanedae e Sanchezia nobilis. Dentro do grupo, observou-se a predominância de visitas de beija-flores a espécies não-ornitófilas que, segundo os autores, pode estar relacionada à escassez desse tipo de espécie, levando os animais a adotarem um hábito alimentar mais generalista, pois as espécies nãoornitófilas têm capacidade de fornecer néctar com valor energético similar ao de espécies polinizadas por beija-flores.

Os autores afirmam, ainda, que o ambiente urbano, no estudo, seria mais favorável à sobrevivência de espécies de beija-flores de caráter generalista, pois as paisagens urbanas parecem ser ocupadas, principalmente, por espécies de menores exigências ecológicas em relação ao alimento e capazes de se adaptar a ambientes abertos. Ao contrário de comunidades de beija-flores mais especializadas ou associadas a ambientes florestais, que podem sofrer redução no número de espécies, uma vez que a disponibilidade de alimento na cidade não garantiria sua sobrevivência. Tais aspectos podem ser encarados como um processo co-evolutivo desenvolvido entre plantas e beija-flores, sendo o emprego de espécies que florescem e produzem néctar durante os períodos de escassez, principalmente no inverno, como por exemplo a Erythrina speciosa (Corticeira-mulungú), uma importante estratégia no planejamento de instrumentos para conservação de pássaros nectaríferos em áreas urbanas (Mendonça \& Anjos, 2006).

Segundo Bortoleto (2004), a presença de avifauna e a formação de ninhos por pássaros, em árvores urbanas, é um dos principais indicadores de qualidade de vida e ambiental nas cidades. Em seu estudo de inventário quali-quantitativo da arborização viária na Estância de Águas de São Pedro, SP, o percentual total de ninhos nas árvores das vias públicas foi de apenas 0,5\%, sendo que as espécies que apresentaram maiores percentuais na presença de ninhos foram: Sibipiruna (Caesalpinia peltophoroides) 33,3\%; Sabão-de- 
Soldado (Sapindus saponaria) 9,5\%; Flamboyant (Delonix regia) 9,5\%. Isso se atribui ao fato de que a diversidade de espécies vegetais empregadas na arborização das cidades brasileiras tem sido relativamente baixa, prevalecendo homogeneidade (Silva Filho \& Bortoleto, 2005).

Guimarães (2006) afirma que é preciso encontrar estratégias, dentro dos centros urbanos, que permitam compatibilizar as exigências da vida humana e a necessidades ecológicas de outras espécies, sendo que, para isto, é necessário que haja um movimento generalizado na direção de se instituir mais parques, arborizar as cidades de forma a possibilitar a sobrevivência de uma maior diversidade de organismos. O aumento das áreas verdes viria a causar o aumento na população de aves, além de que, a existência de árvores floridas atrairia insetos essenciais para certas espécies de aves; além disso, um bairro bem arborizado proporciona mais abrigo e alimentação do que áreas de pasto.

Dentro deste cenário, Oliveira (1990) indica que o plano diretor de uma cidade deve levar em conta todas as vantagens que a arborização pública traz à população e à avifauna nativa, contemplando, em suas diretrizes políticas, metas que norteiem o gerenciamento sustentável das áreas verdes, onde a vegetação se caracterize a mais diversificada possível quanto a períodos de floração, frutificação e porte.

Além disso, o simples fato de uma pessoa, ao sair de sua casa, observar uma árvore florida, ouvir os pássaros cantando, respirar ar puro e sentir prazer em estar naquele lugar, amenizando o estresse da vida urbana agitada, já é gratificante para qualquer ação tomada nesse sentido (Brun \& Brun, 2006).

\section{CONSIDERAÇÕES FINAIS}

Com base nos aspectos observados no presente artigo de revisão, pode-se considerar que:

-As principais funções desenvolvidas pela arborização na manutenção da fauna nos centros urbanos brasileiros seriam no sentido de garantir a função de abrigo e principalmente, de diversificação de fontes de alimentação;

-Observou-se que espécies de hábitos generalistas são extremamente beneficiadas no ambiente urbano, em detrimento das espécies de hábitos específicos, como as espécies típicas de habitats florestais;

-A arborização urbana também desempenha a importante função de complemento de fontes alimentares a espécies típicas de matas nativas, por exemplo, espécies que habitam matas nativas circundantes aos centros urbanos;

-Coloca-se como de primeira importância o aumento de áreas verdes, parques e de arborização de vias públicas, para uma maior diversificação das fontes alimentares, e de 
condições para a manutenção da biodiversidade da fauna urbana; deve-se primar por uma maior diversificação de espécies vegetais, nos planos de arborização, através da priorização do emprego de espécies típicas da flora nativa, além da necessidade do emprego de plantas de caráter perene, para diminuir a rotatividade de práticas de jardinagem, como a substituição de espécies, que pode ocasionar perda de fontes alimentares para a entomofauna, gerando a migração e redução de espécies;

-Em especial, para a arborização de vias públicas, recomenda-se que não se utilize a prática do emprego de apenas uma espécie para arborização da via, mas sempre mais de uma espécie, pois estas árvores terão como função servir de corredor ecológico urbano de espécies da fauna dentro do ambiente. Isso vale, também, para praças, áreas verdes e parques.

\section{REFERÊNCIAS BIBLIOGRÁFICAS}

AGOSTINI, K.; SAZIMA, M. Plantas ornamentais e seus recursos para abelhas no Campus da Universidade Estadual de Campinas, Estado de São Paulo, Brasil. Bragantia. v. 62, n. 3, p. $335-343.2003$.

BORTOLETO, S. Inventário quali-quantitativo da arborização viária da Estância de Águas do São Pedro - SP. (Mestrado em Agronomia), 85 f. Programa de Pós-Graduação em Agronomia - Universidade de São Paulo - Escola Superior de Agricultura "Luiz de Queiroz", Piracicaba, SP. 2004.

BRUN, E.J.; BRUN, F. G. K. Arborização Urbana \& Qualidade de vida. Conselho em Revista. Porto Alegre, RS. Ano 3, n. 18, p. 27. 2006.

JAPYASSÚ, H. F.; BRESCOVIT, A. Biodiversidade araneológica na cidade de São Paulo: a urbanização afeta a riqueza de espécies? 3 p. Disponível: www.ambientebrasil.com.br. Acessado em: 21/04/2006.

FRANCHIN, A. G.; OlIVEIRA, G. M.; MELO, C.; TOMÉ, C. E. R.; MARÇAL JÚNIOR, O. Avifauna do Campus Umuarama, Universidade Federal de Uberlândia, MG. Revista Brasileira de Zoociências. v. 6, n. 2, p 219 - 230. 2004.

FRANCHIN, A. G.; MARÇAL JÚNIOR, O. A riqueza da avifauna no Parque Municipal do Sábia, zona urbana de Uberlândia (MG). Biotemas. v. 17, n. 1, p. 179 - 202. 2004. 
GUIMARÃES, M. Há mais aves nos grandes centros urbanos hoje? Ciência \& Cultura. v. 58, n. 2, Abril/Junho, 2006.

LIMA, F. C. T.; ALEIXO, A. Notas sobre algumas aves em ambientes antropizados da cidade de Campinas, São Paulo, Brasil. Boletim do Centro de Estudos Ornitológicos (CEO). n. 14 , p. $2-6.2000$.

LOMBARDO, M. A. Vegetação e clima. In: III ENCONTRO NACIONAL SOBRE ARBORIZAÇÃO URBANA. Anais... Curitiba, PR. p. 01 -13. 1990.

MENDONÇA, L. B.; ANJOS, L. Beija-flores (Aves, Trochilidae) e seus recursos florais em uma área urbana do Sul do Brasil. Revista Brasileira de Zoologia. v. 22, n. 1, p. $51-59$. 2005.

MENDONÇA, L. B.; ANJOS, L. Feeding behavior of hummingbirds and perching birds on Erythrina speciosa Andrews (Fabaceae) flowers in urban area, Londrina, Paraná, Brazil. Revista Brasileira de Zoologia. v. 23, n. 1, p. 42 - 49. 2006.

OLIVEIRA, M. M. A. Arborização e avifauna urbana em cidades do interior paulista. Boletim do Centro de Estudos Ornitológicos (CEO). n. 7, p. 10 - 14. 1990.

PEREIRA, G. A.; MONTEIRO, C. S.; CAMPELO, M. A.; MEDEIROS, C. O uso de espécies vegetais, como instrumento de biodiversidade da avifauna silvestre, na arborização pública: o caso do Recife. Atualidades Ornitológicas. n. 125, p. 10 - 18. 2005.

RUSZCZYK, A.; NASCIMENTO, E. S. Biologia dos adultos Methona themisto (Hübner, 1818) (Lepidoptera, Nymphalidae) em praças públicas de Uberlândia, Minas Gerais, Brasil. Revista Brasileira de Biologia. v. 59, n. 4. p. 577 - 583. 1999.

SILVA FILHO, D. F.; BORTOLETO, S. Uso de indicadores de diversidade na definição de plano de manejo da arborização viária de Águas de São Pedro - SP. Revista Árvore. v. 29, n. 6 , p. $973-982.2005$.

SILVA, R. S.; MAGALHÃES, H. Ecotécnicas urbanas. Ciência \& Ambiente. n. 7, p. 33 -42. 1993. 
SOUZA, S. G. X.; TEIXEIRA, A. F. R.; NEVES, E. L.; MELO, A. M. C. As abelhas sem ferrão (Apidae: Meloponina) residentes no Campus Federação/Ondina da Universidade Federal da Bahia, Salvador, Bahia, Brasil. Candombá - Revista Virtual. v. 1, n. 1, p. 57 - 69. 2005.

TAURA, H. M.; LAROCA, S. A associação de abelhas silvestres de um biótopo urbano de Curitiba (Brasil), com comparações espaço-temporais: abundância relativa, fenologia, diversidade e explotação de recursos (Hymenoptera, Apoidea). Acta Biológica Paranaense. v. 30, n. 1,2,3,4. p. 35 - 137. 2001. 